\title{
Identification of Zoonotic Tick-Borne Pathogens from Korean Water Deer (Hydropotes inermis argyropus)
}

\author{
Seung-Uk Shin, ${ }^{1, *}$ Yu-Jin Park, ${ }^{2, *}$ Ji-Hyoung Ryu, ${ }^{1, *}$ Dong-Hun Jang, ${ }^{2}$ Sunwoo Hwang, ${ }^{2}$ \\ Hyung-Chul Cho, Jinho Park, Jae-lk Han, ${ }^{4}$ and Kyoung-Seong Choi ${ }^{1,2}$
}

\begin{abstract}
Korean water deer (Hydropotes inermis argyropus) are widespread in the Republic of Korea (ROK). Mostly, Korean water deer are essential hosts for maintaining ticks and tick-borne diseases (TBDs). Here, we investigated the prevalence of tick-borne pathogens (TBPs) among rescued Korean water deer. Anaplasma phagocytophilum (21.4\%, 6/28), Anaplasma capra (14.3\%, 4/28), Babesia capreoli (3.6\%, 1/28), and Coxiella burnetii $(3.6 \%, 1 / 28)$ were detected, but Borrelia burgdorferi, Ehrlichia, Rickettsia, and Theileria infections were not found. A. phagocytophilum was the most commonly detected pathogen, and co-infection with A. capra and B. capreoli was also noted in one Korean water deer. To our knowledge, this is the first article of $B$. capreoli infection in Korean water deer in the ROK. The infecting isolate of A. phagocytophilum was genetically characterized by $16 \mathrm{~S}$ ribosomal RNA (rRNA) gene and ankyrin-related protein (ankA) gene. Although the $16 \mathrm{~S}$ rRNA gene alone may not be informative enough to delineate distinct host species, ankA-based phylogeny revealed a high identity of Korean water deer sequences with those of the causative agent of human granulocytic anaplasmosis. A. capra was detected by using citrate synthase gene ( gltA), heat-shock protein ( $g r o E L)$, and major surface protein 4 ( $m s p 4)$ genes. Phylogenetic tree based on these gene markers revealed that there were at least two distinct variants within A. capra circulating in the ROK. One variant originated from different hosts including humans, ticks, goats, and sheep, whereas the other variant was reported recently in Korean water deer in the ROK. Consequently, these sequences were identified to belong to a zoonotic species. Sequencing analysis of the 18S rRNA gene revealed that our isolate belonged to B. capreoli and was distinct from Babesia divergens and Babesia venatorum. Moreover, our isolate showed $92.2 \%$ homology with $B$. capreoli sequences, indicating that these differences may be attributed to the different tick species that transmit $B$. capreoli or to different host species. Genotyping and phylogenetic analysis of $C$. burnetii based on 16S rRNA and IS1111 genes revealed that our isolate was grouped with several strains of $C$. burnetii and was genetically distant from Coxiella-like bacteria isolates. The present results highlight that Korean water deer act as potential reservoir hosts for zoonotic TBPs, and thus play an important role in the transmission of TBDs in humans, animals, and livestock.
\end{abstract}

Keywords: Anaplasma phagocytophilum, Anaplasma capra, Babesia capreoli, Coxiella burnetii, Korean water deer

\section{Introduction}

$\mathbf{K}$ OREAN WATER DEER (Hydropotes inermis argyropus) are widespread and are the most commonly rescued wild animals in the Republic of Korea (ROK) (Seong et al. 2015). The Korean water deer has been classified as a vulnerable species and is included in the International Union for
Conservation of Nature and Natural Resources Red List worldwide, except the ROK. Owing to the absence of higher predators in the ROK, the population of Korean water deer is growing steadily (Kim et al. 2011). The scarcity of food and natural habitat has led to frequent access to farmland; consequently, the economic damage caused by Korean water deer is also increasing. Korean water deer are reportedly essential

Departments of ${ }^{1}$ Animal Science and Biotechnology and ${ }^{2}$ Horse/Companion and Wild Animals, College of Ecology and Environmental Science, Kyungpook National University, Sangju, Republic of Korea.

${ }^{3}$ Department of Veterinary Internal Medicine, College of Veterinary Medicine, Jeonbuk National University, Iksan, Republic of Korea.

${ }^{4}$ Laboratory of Wild Medicine, College of Veterinary Medicine, Jeonbuk National University, Iksan, Republic of Korea.

*These authors contributed equally to this work. 
in maintaining and amplifying tick populations, which, in turn, leads to the tick-borne diseases (TBDs) vectored by these ticks. Several studies reported that Korean water deer may act as a major reservoir of various tick-borne pathogens (TBPs) that can infect humans and domesticated animals (Kang et al. 2011, Ko et al. 2013, Han et al. 2017, VanBik et al. 2017).

Anaplasma is transmitted by ticks and has a wide range of hosts infecting animals and humans. Among the several Anaplasma species, Anaplasma phagocytophilum and Anaplasma bovis infections have been mainly reported among wild ruminants in the ROK (Lee et al. 2009, Kang et al. 2011, Seong et al. 2015, Lee et al. 2018); recently, Anaplasma capra has been identified in Korean water deer (Amer et al. 2019). Mostly, A. phagocytophilum is considered to have the highest zoonotic potential and is the causative agent for tickborne fever in domestic ruminants. In addition, A. capra has also been shown to cause infection in humans ( $\mathrm{Li}$ et al. 2015). Both A. phagocytophilum and A. capra infections in cervids are asymptomatic.

Babesia are an intraerythrocytic protozoa that is transmitted by Ixodes ticks and is highly pathogenic to ruminants, horses, pigs, dogs, cats, and, in some cases, humans (Caccio et al. 2000). The clinical signs vary from asymptomatic infections to acute infections and can lead to death in severe cases (Zintl et al. 2003, Penzhorn 2006). Although Babesia is primarily of veterinary importance, it is described as potentially zoonotic and causes a malaria-like disease in humans (Lempereur et al. 2012). Various wild animals are reservoir hosts for zoonotic babesiosis, and among them, Babesia divergens, Babesia capreoli, and Babesia venatorum have been reportedly transmitted via wild cervids in Europe (Razanske et al. 2019). Moreover, despite posing a threat to animals and public health, babesiosis has rarely been studied in the ROK.

Coxiella burnetii is the causative agent for $\mathrm{Q}$ fever in humans and a highly infectious zoonotic bacterium that can affect different species of wild and domestic animals. Transmission of $C$. burnetii is by tick bite or exposure to infected excreta expelled by ticks onto the skin of the animal host as they feed (Norlander 2000, Fard and Khalili 2011). Interestingly, the main transmission route from ticks to humans is considered to be inhalation of the contaminated fecal material from ticks (Fard and Khalili 2011, Sprong et al. 2012). Domestic animals such as cattle, sheep, and goats are the primary reservoirs associated with the occurrence of C. burnetii (Eldin et al. 2017). C. burnetii prevalence in wild animals has been ignored, despite the evidence that wildlife, including cervids, act as true reservoirs for $C$. burnetii.

Recently, the occurrence of various TBPs is rapidly increasing worldwide due to climate change and global warming. These TBPs can infect humans and numerous animals, including livestock, companion animals, and wild mammals. Of these, Anaplasma, Babesia, Borrelia, Coxiella, Ehrlichia, Rickettsia, and Theileria are the most common TBPs, and most of these pathogens are zoonotic. Despite being a threat to animals and public health, to date, only a few studies have been conducted on TBDs in the ROK. This study investigated the prevalence of TBPs among rescued Korean water deer and assessed whether Korean water deer could serve as reservoirs of TBPs. Further, we sought to contribute information to the literature regarding the diversity of TBPs infecting Korean water deer in the ROK.

\section{Materials and Methods}

\section{Ethical approval}

This study was exempt from ethical approval from the Institutional Animal Care and Use Committee (IACUC) at Kyungpook National University, because the IACUC at this University only evaluates laboratory animals maintained within indoor facilities and not outdoor animals.

\section{Sample collection}

In the fall of 2018, Korean water deer that were accidentally killed on the roads arrived at Jeonbuk Wildlife Rescue Center. A total of 28 blood samples were collected from the Korean water deer and were sent to the Animal Immunology laboratory of Kyungpook National University. Of these 28 samples, 11 and 12 were derived from females and males, respectively. However, gender information was not recorded for five of the samples.

\section{DNA extraction, PCR, and nucleotide sequencing}

DNA was extracted from the blood samples by using DNeasy Blood Kits (Qiagen) according to the manufacturer's instructions. TBPs were screened by using specific primer sets for Anaplasma spp., Babesia spp., Borrelia burgdorferi, C. burnetii, Ehrlichia spp., Rickettsia spp., and Theileria luwenshuni (Table 1). Anaplasma, Ehrlichia, and Rickettsia infection was detected by using an AccuPower Rickettsiales 3-Plex PCR Kit (Bioneer, Daejeon, ROK). Positive samples of Anaplasma spp. were further amplified by using $16 \mathrm{~S}$ ribosomal RNA (rRNA) genes (EE1/EE2 and EE3/EE4) and ankyrin-related protein (ankA) gene for A. phagocytophilum and citrate synthase gene ( $g l t A)$, heat-shock protein ( $g r o E L)$, and a major surface protein 4 ( $m s p 4)$ for A. capra. Babesia spp. was tested by using the $18 \mathrm{~S}$ rRNA gene. The positive sample for the $18 \mathrm{~S}$ rRNA gene was screened by using a primer of $B$. divergens designed in this study (Table 1). $C$. burnetii was screened by using the IS1111 (transposase insertion element) and $16 \mathrm{~S}$ rRNA genes. In all of the experiments, negative and positive controls were also included in the PCR runs. All PCR products were separated by electrophoresis on $1.5 \%$ agarose gels and visualized after staining with ethidium bromide. The PCR products were purified by using an AccuPrep ${ }^{\circledR}$ PCR Purification Kit (Bioneer) in accordance with the manufacturer's instructions and directly sequenced (Macrogen, Inc.). In this study, only samples with a good sequencing result were considered to be positive for each pathogen.

\section{Phylogenetic analysis}

The nucleotide sequences obtained in this study were analyzed by using BioEdit (version 7.2.5) and the Basic Local Alignment Search Tool available from the National Center for Biotechnology Information database. To investigate the homology among the genes from $A$. phagocytophilum, A. capra, B. capreoli, and C. burnetii, nucleotide sequences were aligned by using ClustalX and then analyzed via direct comparison with reference sequences from GenBank. A phylogenetic tree was constructed based on nucleotide alignments by using the maximum-likelihood method. 


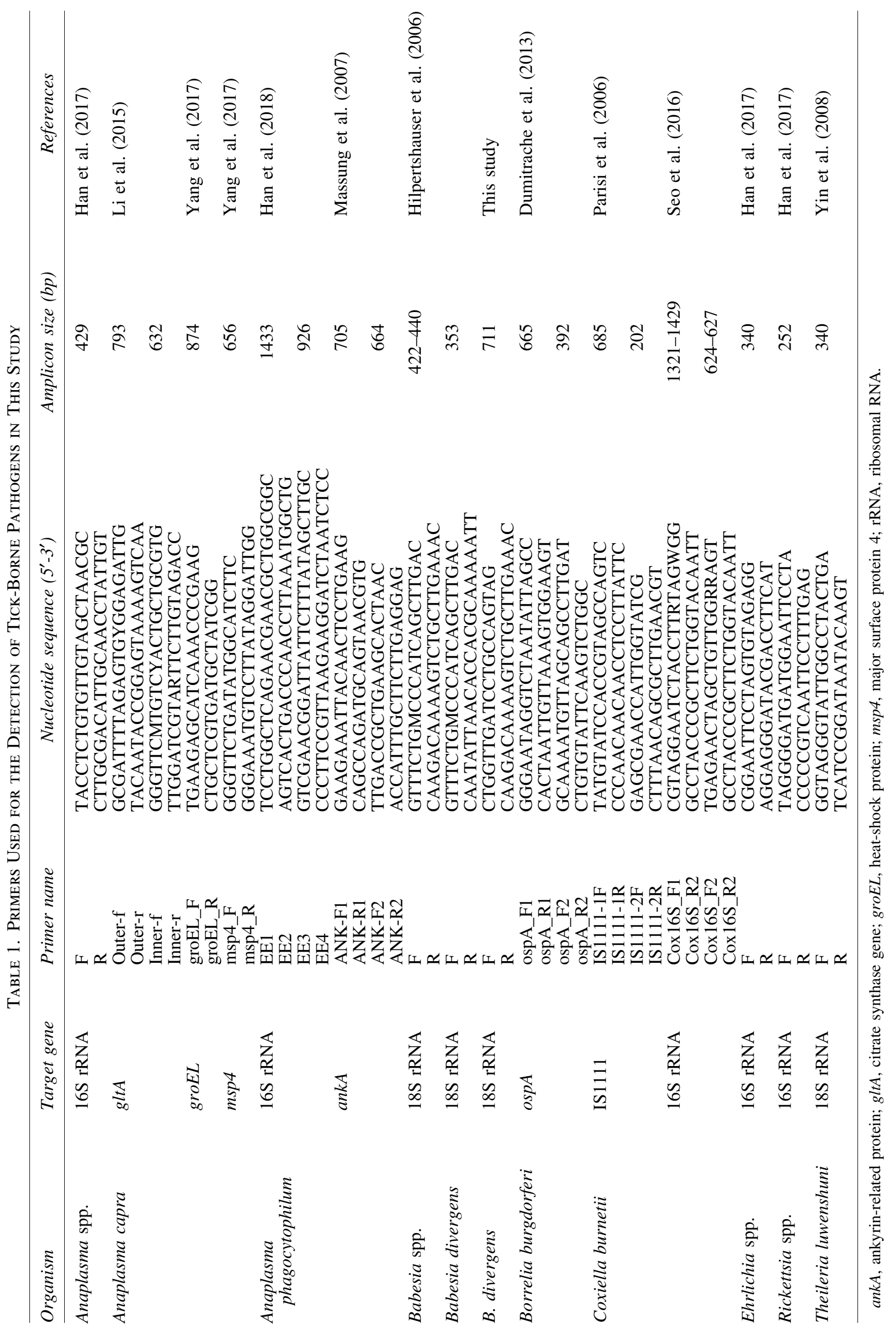


Bootstrap analysis was conducted with 1000 replicates by using MEGA version 7 software (Kumar et al. 2016).

\section{Results}

\section{Prevalence of TBPs in Korean water deer}

Of the TBPs examined, A. phagocytophilum, A. capra, $B$. capreoli, and C. burnetii were detected in $6(21.4 \%), 4$ (14.3\%), 1 (3.6\%), and 1 (3.6\%) Korean water deer, respectively. However, B. burgdorferi, Ehrlichia, Rickettsia, and Theileria infections were not found in these animals (Table 2). Positive samples for each pathogen were identified to be positive in both PCR and sequence analysis. Coinfection with $A$. capra and $B$. capreoli was detected in one $(3.6 \%)$ Korean water deer. To the best of our knowledge, this is the first article of $B$. capreoli in Korean water deer. Interestingly, A. capra infection was more commonly detected in males. However, no difference was found in the prevalence of A. phagocytophilum infection between the female and male infections; this was likely a result of the gender information being incomplete.

\section{A. phagocytophilum infections}

Anaplasma spp. was first investigated to detect A. phagocytophilum infection (Table 2). Six animals were positive for Anaplasma spp. and these were confirmed as A. phagocytophilum via sequencing analysis (Fig. 1). Specific primers for A. phagocytophilum were used for further analysis. A. phagocytophilum was detected in six and two Korean water deer by using the $16 \mathrm{~S}$ rRNA and ankA genes, respectively (Table 2). The phylogenetic tree based on the 16S rRNA gene showed that one isolate (KWD26) was grouped with the tick, CWD, and KWD isolates reported in the ROK, sharing a similarity of 98.8-99.4\% with the other, whereas the other five isolates formed a separate clade and were 91.7-98.3\% homologous with several Korean isolates (KR611598, GU556621, MH338209, MH338210, and MH338211) (Supplementary Fig. S1). Genetic variations within A. phagocytophilum of Korean water deer were identified in the ROK. On the contrary, among the $16 \mathrm{~S}$ rRNA gene, only two were amplified with the ankA gene, and these sequences (KWD17 and KWD22) showed 99.8-100\% identity with the human isolates identified in the ROK (MH015219 and KT986059) and were grouped with Asian isolates (Supplementary Fig. S2).

\section{A. capra infections}

A. capra infection was found in four samples based on the 16S rRNA gene of Anaplasma spp. (Fig. 1). Next, A. capra was detected in four, two, and two Korean water deer by using gltA, groEL, and msp4 genes, respectively (Table 2). Based on the gltA gene, our isolates were divided into two clades (Fig. 2). One clade included three isolates, and the other clade was only one isolate. The three isolates (KWD3, KWD11, and KWD19) were more closely related to the recently reported Korean water deer isolates and showed 96.8$98.9 \%$ homology with these isolates, whereas one isolate (KWD9) had diverged from Korean water deer isolates and was clustered with goats, sheep, and ticks originating from China. Of the two groEL gene sequences, KWD9 shared 98.7-98.9\% similarity with the cattle, goats, sheep, and tick isolates, whereas KWD19 showed $96.2 \%$ homology with the Korean water deer isolates and $88 \%$ similarity with the other reference strains mentioned earlier (Supplementary Fig. S3). The sequences for the 2 msp 4 genes were different among 11 nucleotides, and these sequences shared 98.7-99.0\% similarity with the human (KM206277), goat (MH174933), tick (KR261640), and Korean water deer (LC432231) isolates (Supplementary Fig. S4).

\section{B. capreoli infection}

Initially, PCR with primers for the detection of a broad range of Babesia spp. was performed (Table 1). DNA of Babesia spp. was detected in one Korean water deer. PCR was performed again by using specific primers to detect $B$. divergens, and the presence of $B$. divergens was revealed in one sample. This sample was sequenced and included in the phylogenetic tree. According to the phylogenetic analysis based on the 18S rRNA gene sequences, our isolate was found to belong to $B$. capreoli rather than $B$. divergens and was distinct from $B$. divergens, $B$. venatorum, and other known Babesia species (Fig. 3). Our isolate showed $92.2 \%$

Table 2. Tick-Borne Pathogens Identified in Korean Water Deer

\begin{tabular}{|c|c|c|c|c|c|c|c|c|c|c|c|}
\hline \multirow[b]{2}{*}{ Sample } & \multirow[b]{2}{*}{ Gender } & \multirow{2}{*}{$\begin{array}{c}\text { Anaplasma } \\
\text { spp. }\end{array}$} & \multicolumn{2}{|c|}{$\begin{array}{c}\text { Anaplasma } \\
\text { phagocytophilum }\end{array}$} & \multicolumn{3}{|c|}{ Anaplasma capra } & \multicolumn{2}{|c|}{ Babesia } & \multicolumn{2}{|c|}{ Coxiella burnetii } \\
\hline & & & $16 S$ rRNA & ankA & gltA & groEL & msp4 & $18 S$ rRNA & Babesia capreoli & $16 S r R N A$ & IS1111 \\
\hline 2 & M & + & + & - & - & - & - & - & - & - & - \\
\hline 3 & $\mathrm{~F}$ & + & - & - & + & - & - & - & - & - & - \\
\hline 5 & $\mathrm{~F}$ & - & - & - & - & - & - & - & - & + & + \\
\hline 9 & $\mathrm{M}$ & + & - & - & + & + & + & - & - & - & - \\
\hline 11 & M & + & - & - & + & - & - & - & - & - & - \\
\hline 15 & $\mathrm{~F}$ & + & + & - & - & - & - & - & - & - & - \\
\hline 16 & M & + & + & - & - & - & - & - & - & - & - \\
\hline 17 & $\mathrm{~F}$ & + & + & + & - & - & - & - & - & - & - \\
\hline 19 & M & + & - & - & + & + & + & + & + & - & - \\
\hline 22 & None & + & + & + & - & - & - & - & - & - & - \\
\hline 26 & $\mathrm{~F}$ & + & + & - & - & - & - & - & - & - & - \\
\hline Total & & 10 & 6 & 2 & 4 & 2 & 2 & 1 & 1 & 1 & 1 \\
\hline
\end{tabular}

+, Both PCR and sequencing analysis; -, not detected; F, female; M, male; None, gender information is not obtained. 
FIG. 1. Phylogenetic analyses of the 16S rRNA sequences from Anaplasma spp. obtained in this study. The tree was constructed by using the MEGA7 software by employing the maximumlikelihood method. Numbers at the nodes of the tree indicate bootstrap values as a percentage of 1000 replicates that support each phylogenetic branch. The isolates identified in this study are marked in bold type as a circle symbol. rRNA, ribosomal RNA.

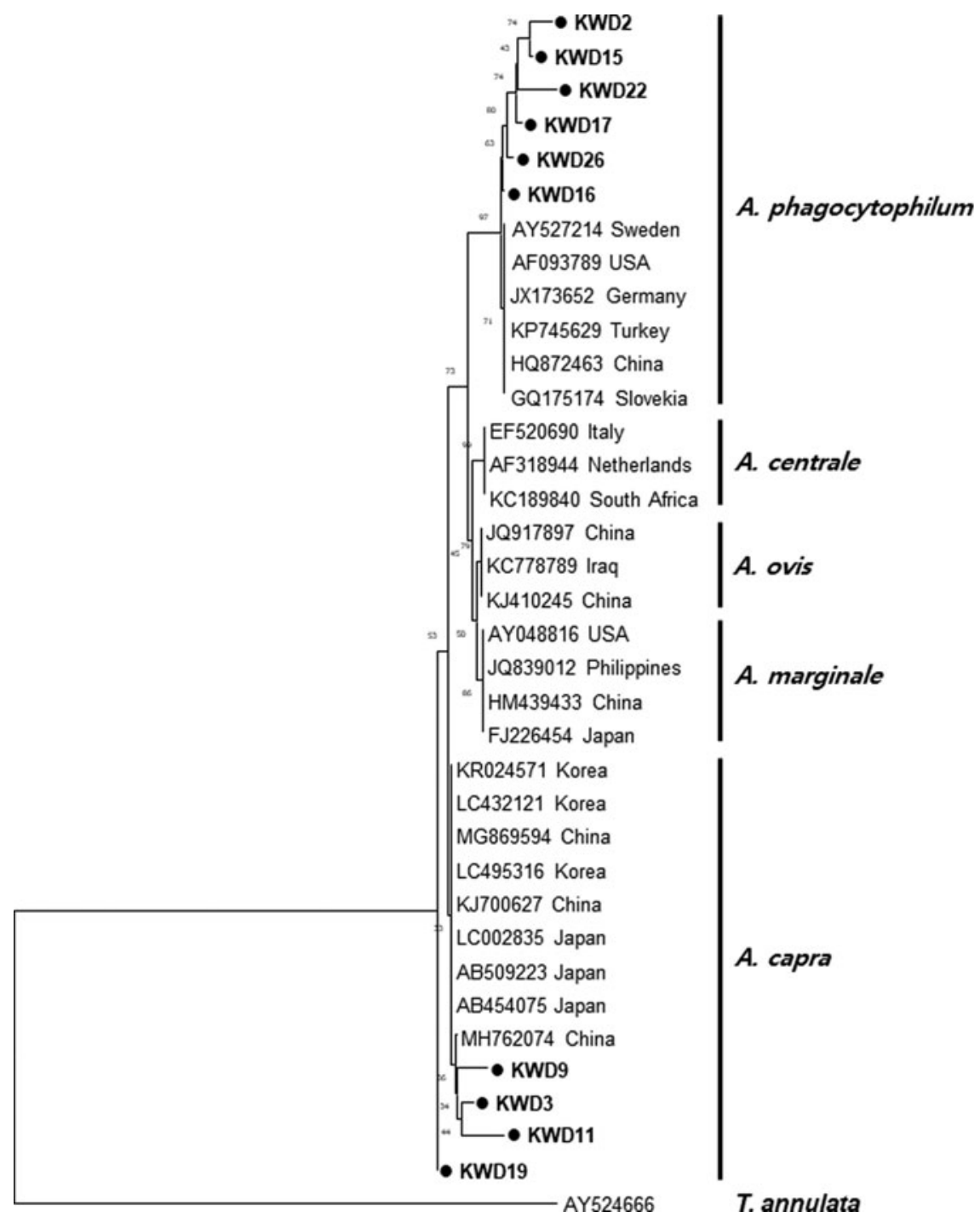

homology with the B. capreoli strains/isolates obtained from several other countries.

\section{C. burnetii infection}

Among the 28 Korean water deer examined by using both $16 \mathrm{~S}$ rRNA and IS1111genes, only 1 sample was positive for C. burnetii (Table 2). The phylogenetic tree based on the $16 \mathrm{~S}$ rRNA gene revealed that our isolate shared $100 \%$ identity with a human isolate (KY498541), which was previously reported in the ROK, as well as with several $C$. burnetii strains and belonged to clade A. Isolates/strains that belonged to clades B, C, and D were Coxiella-like bacteria and were mostly identified from ticks (Fig. 4). Based on the IS1111 gene, our isolate was classified into sub-cluster 2 and formed a cluster with the human, cattle, sheep, and tick isolates from several countries (Supplementary Fig. S5). By analyzing the sequences of both 16S rRNA and IS1111 genes, Korean water deer was found to be infected with $C$. burnetii.

\section{Discussion}

Korean water deer have the tendency to invade domestic residences to escape predators due to climatic or environ- mental changes and, consequently, are found even in urban areas (Han et al. 2017). The most important concern with regard to Korean water deer is that these animals are frequently exposed to ticks in mountainous regions and are naturally infected with TBPs and are thereby more likely to transmit TBDs not only to humans but also to livestock in the ROK. To date, several studies have shown that Korean water deer have become infected with various TBPs, and most of which were zoonotic pathogens (Seong et al. 2015, Han et al. 2017, Lee et al. 2018, Amer et al. 2019). This study revealed that A. phagocytophilum, A. capra, B. capreoli, and C. burnetii were detected in Korean water deer, indicating that Korean water deer are reservoir hosts for zoonotic TBPs.

Here, the 16S rRNA and ankA genes were used to detect A. phagocytophilum infection. A previous study mentioned that the 16S rRNA gene was used most often for strain characterization; however, it was not suitable for determining host specificity (Majazki et al. 2013). Phylogenetic analysis of the $16 \mathrm{~S}$ rRNA gene revealed that there were genetic variations among six Korean water deer isolates, but it was difficult to explain the relationship with host specificity. Based on the ankA gene sequences, two Korean water deer isolates identified in this study were clustered with Asian 


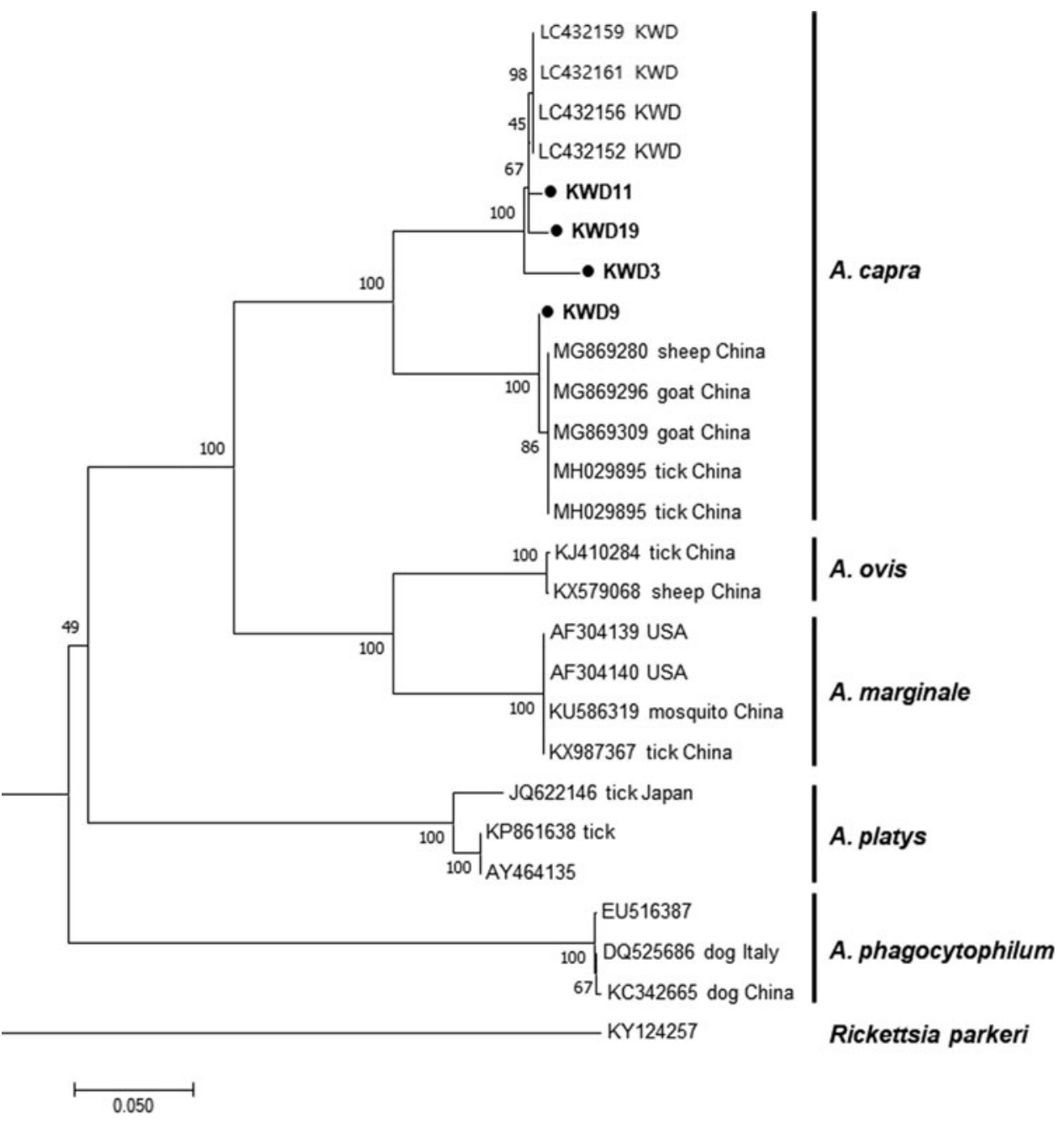

FIG. 2. Phylogenetic trees of Anaplasma capra obtained from the gltA sequences. The tree was constructed by using the MEGA7 software by the maximum-likelihood method. Numbers at the nodes of the tree indicate bootstrap values as a percentage of 1000 replicates that support each phylogenetic branch. Our isolates identified in this study are marked in bold type as a circle symbol. gltA, citrate synthase gene. strains and distinct from European and North American strains. Mostly, one of our isolates showed 100\% identity with the sequence of the causative agent of a human case of granulocytic anaplasmosis isolated in the ROK. Although we could not achieve an exact conclusion because we did not analyze ankA gene clusters in this study, it is speculated that two Korean water deer may belong to cluster I. The ankA gene sequences were separated into five different gene clusters I-V. Of them, humans, dogs, horses, and cats were grouped in cluster I, whereas ruminants were much more diverse and belonged to clusters I, II, III, IV, and V (Majazki et al. 2013). The present results indicated that the $16 \mathrm{~S} \mathrm{rRNA}$ gene did not provide enough information for delineating $A$. phagocytophilum clustering based on the host species; consequently, for confirming the potential zoonotic host, it is necessary to analyze the ankA-based phylogeny. Because A. phagocytophilum infection was reportedly prevalent among Korean water deer (Kang et al. 2011, Seong et al. 2015, Lee et al. 2018), this animal was considered a reservoir host for A. phagocytophilum. Our results suggest that Korean water deer harbor A. phagocytophilum that may be infectious for humans, dogs, horses, and livestock; thus, they could be relevant reservoirs for granulocytic anaplasmosis in humans and domestic animals in the ROK.
A. capra was first identified in goats and considered a novel tick-transmitted zoonotic pathogen (Li et al. 2015). Here, A. capra infection was analyzed based on the gltA, groEL, and $m s p 4$ genes, and our findings indicated that there were at least two variants of $A$. capra circulating in the ROK. One variant originated from various hosts, including humans, ticks, goats, and sheep, whereas the other variant was found only in Korean water deer reported by another group (Amer et al. 2019). This could be explained by the different tick vectors that transmit this pathogen. Consequently, in this study, A. capra was confirmed as a zoonotic species. A. capra was widely distributed in China and detected in Ixodes persulcatus, Haemaphysalis longicornis, Haemaphysalis qinghaiensis, and Rhipicephalus microplus as well as goats and sheep (Sun et al. 2015, Yang et al. 2016, Lu et al. 2017). In Japan, A. capra was also found in the free-living Capricornis crispus and deer (Sato et al. 2009). Recently, A. capra was detected in Korean water deer and cattle in the ROK (Seo et al. 2018, Amer et al. 2019), and it rapidly emerged as a zoonotic pathogen; however, the specific species of ticks that carry A. capra in the ROK have not yet been elucidated. $H$. longicornis is the most frequently collected tick species in the ROK, indicating that this tick might serve as a vector for A. capra. Along with climate change, tick species are 
FIG. 3. Phylogenetic tree of the partial 18S rRNA gene sequences of $B a$ besia using the maximum-likelihood method. The numbers over the branches indicate bootstrap values as a percentage of 1000 replicates that support each phylogenetic branch. Our isolate identified in this study is marked in bold type as a circle symbol.

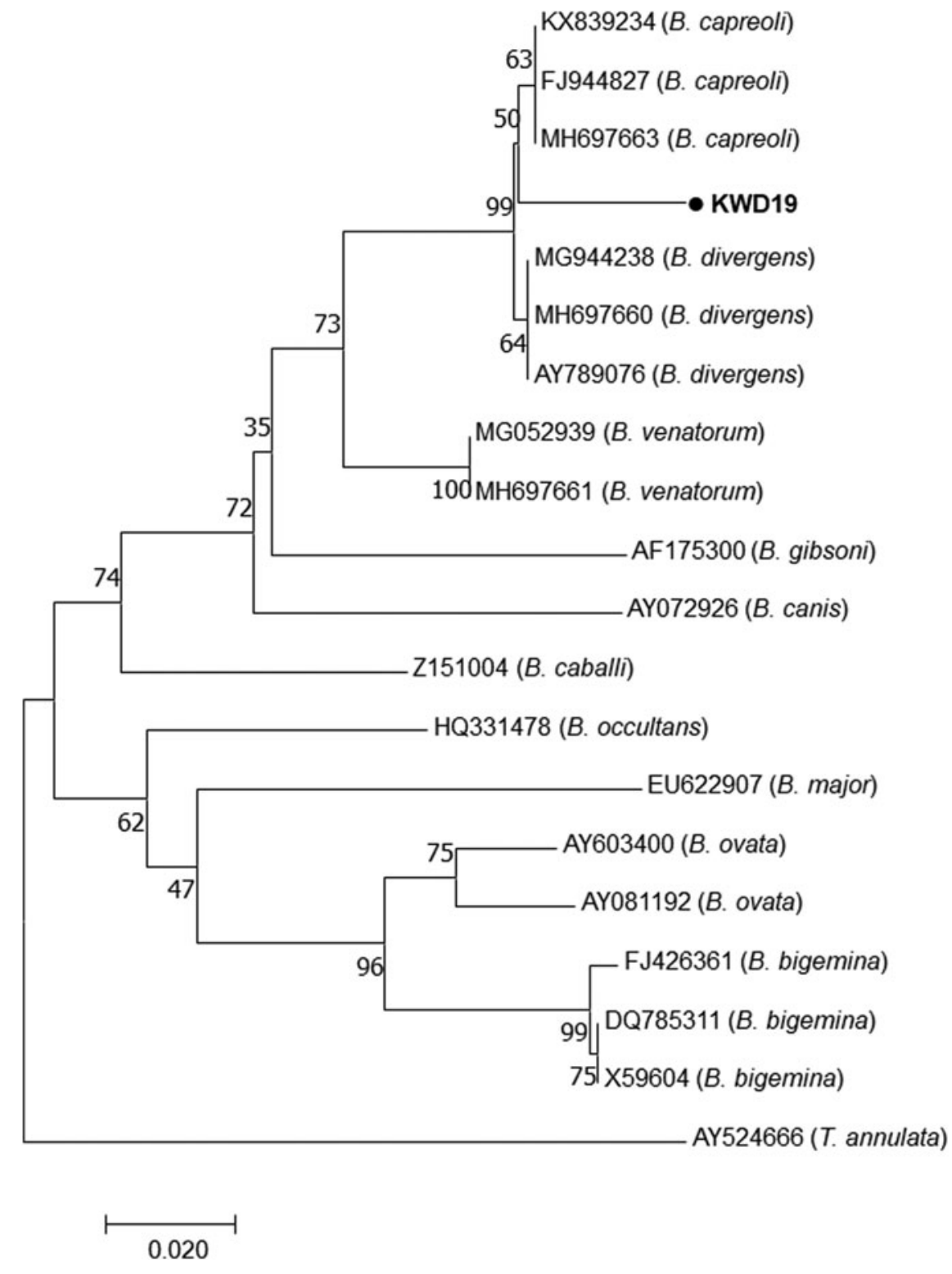

expanding their geographical distribution, and, subsequently, an increased risk of TBPs is likely to be a growing concern for humans and animal health (Chvostac et al. 2018, JaimesDuenez et al. 2018). Consequently, Korean water deer could be considered as a potential reservoir for A. capra. Further studies are necessary to investigate the epidemiology and pathogenicity of $A$. capra circulating in the ROK.

We found that one Korean water deer was infected by B. capreoli. This was the first study to report the presence of $B$. capreoli in the ROK. The PCR results revealed that our isolate was $B$. divergens. To confirm $B$. divergens, we again performed PCR by using the primers for $B$. divergens, followed by sequence analysis. The unexpected result was that our sample was confirmed to be $B$. capreoli. B. divergens is highly similar to $B$. capreoli, and these two species differed by only three nucleotides in the $18 \mathrm{~S}$ rRNA gene (Malandrin et al. 2010). B. capreoli and B. divergens could not be differentiated based on morphology or serology, and to identify these species, sequence analysis was warranted (Andersson et al. 2016). However, phylogenetic analysis revealed that our isolate showed $92.2 \%$ homology with sequences belonging to $B$. capreoli, indicating that this difference can be attributed to a different tick species that transmit B. capreoli or to different host species. Here, we could not conclude as to how this pathogen was introduced into the ROK. It is possible that Babesia has been overlooked because babesiosis has never been reported in the ROK, and the diagnosis of Babesia infection has primarily been restricted to grazing cattle. $B a$ besia spp. are found in a wide range of hosts, including rodents, cottontail rabbits, small mammals, cattle, and even birds (Homer et al. 2000). It is speculated that wild animals may act as competent reservoirs, promote the maintenance of this parasite, and allow transmission to the next generation of feeding ticks. Therefore, it may be worthwhile to elucidate the life cycle and identify the tick vector of $B$. capreoli in the ROK. Consequently, Korean water deer may serve as a reservoir host for $B$. capreoli. To better understand the importance of $B$. capreoli as an infectious agent, it is necessary to 


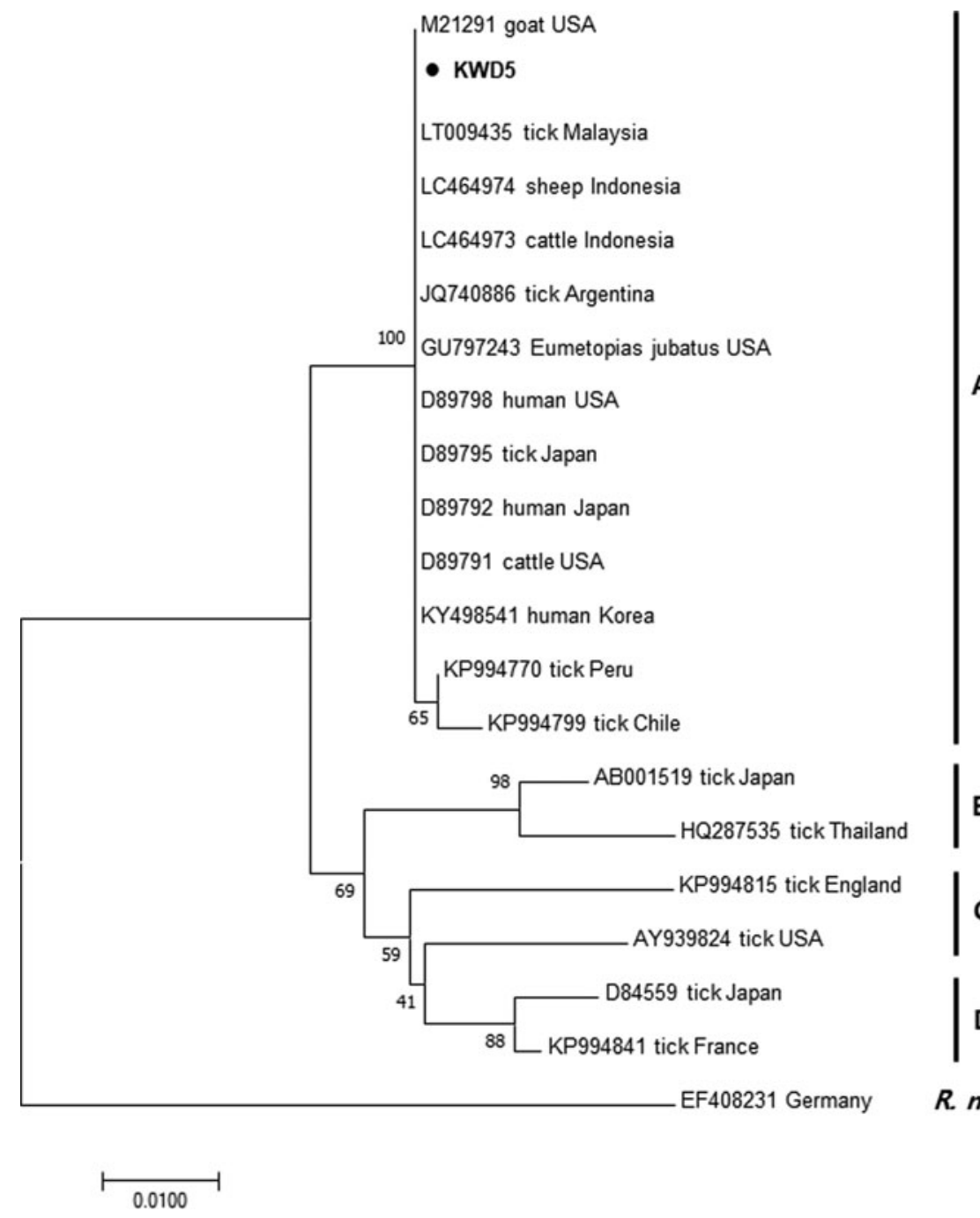

FIG. 4. Phylogenetic analyses based on the $16 \mathrm{~S}$ rRNA sequences of Coxiella burnetii from Korean water deer. The 4 clades (A to $\mathbf{D}$ ) of Coxiella are shown. The tree was constructed by using the MEGA7 software by employing the maximumlikelihood method. Numbers at the nodes of the tree indicate bootstrap values as a percentage of 1000 replicates that support each phylogenetic branch. Our isolates identified in this study are marked in bold type as a circle symbol. investigate its prevalence and pathogenicity in wild and domesticated animals.

In this study, $C$. burnetii infection was detected in only one Korean water deer. This result is different from previous reports in the ROK, which reported $9.18 \%$ seroprevalence and $6.6 \%$ prevalence based on real-time PCR (Shin et al. 2014). The difference between the two groups may be explained by the sample number and the applied diagnostic method. Unfortunately, we could not obtain serum samples, and hence, only Coxiella DNA was detected by using IS1111 and 16S rRNA genes. Based on the 16S rRNA gene, Coxiella genus was divided into four different clades (A-D), with C. burnetii belonging to clade A (Duron et al. 2015b). Phylogenetic analysis revealed that our isolate was included in clade A and diverged from Coxiella-like bacteria (B-D). Except for two tick isolates, all sequences belonging to clade A showed $100 \%$ identity with each other. Tick isolates belonging to clade A, Coxiella-like bacteria and hosted by soft ticks, have served as the progenitor of C. burnetii (Duron et al. 2015a). In addition, the IS1111 gene was also used to distinguish $C$. burnetii from Coxiella-like bacteria. The isolate from Korean water deer was grouped with $C$. burnetii isolates obtained from humans in Greece, cattle in France, and ticks collected from dogs in Serbia. These isolates were genetically distant from Coxiella-like endosymbionts. However, the phylogenetic tree base on the IS1111 gene did not provide enough information compared with the $16 \mathrm{~S}$ rRNA gene. Ticks carry both $C$. burnetii and Coxiella-like bacteria, but Coxiella-like bacteria are exceptionally diverse and widespread in ticks (Duron et al. 2015b). Since it has highlighted the genetic similarities between $C$. burnetii and Coxiella-like bacteria, it is necessary to appropriately discriminate between $C$. burnetii and Coxiella-like bacteria. Given that $C$. burnetii poses a higher infection risk to vertebrates, at least two genes are required for diagnosing C. burnetii. Consequently, our findings suggest that phylogenetic analysis based on the 16S rRNA gene is the most accurate method for $C$. burnetii diagnosis. These results provide evidence that Korean water deer may be reservoirs for the potentially pathogenic and zoonotic C. burnetii.

\section{Conclusions}

This study shows that Korean water deer have been infected with various TBPs, including A. phagocytophilum, A. capra, B. capreoli, and C. burnetii. This is the first article to identify B. capreoli in Korean water deer. The four pathogens identified in this study are of public health concern and 
pose a risk to domestic animals, livestock, and humans via direct contact. Our findings highlight that Korean water deer act as potential reservoirs for TBPs. Continuous surveillance in wild animals is necessary to monitor the risk of zoonotic infection among human and domestic animals and to assess the transmission and spread of zoonotic TBPs as well as the introduction of new pathogens into naive populations of wild animals. Further studies should assess the potential transmission risks and pathogenicity of these TBPs circulating in the ROK.

\section{Author Disclosure Statement}

No conflicting financial interests exist.

\section{Funding Information}

This research was supported by Kyungpook National University Development Project Research Fund, 2019.

\section{Supplementary Material}

Supplementary Figure S1

Supplementary Figure S2

Supplementary Figure S3

Supplementary Figure S4

Supplementary Figure S5

\section{References}

Amer S, Kim S, Yun Y, Na KJ. Novel variants of the newly emerged Anaplasma capra from Korean water deer (Hydropotes inermis argyropus) in South Korea. Parasit Vectors $2019 ; 12: 365$.

Andersson MO, Bergvall UA, Chirico J, Christensson M, et al. Molecular detection of Babesia capreoli and Babesia venatorum in wild Swedish roe deer, Capreolus capreolus. Parasit Vectors 2016; 9:221.

Caccio S, Camma C, Onuma M, Severini C. The beta-tubulin gene of Babesia and Theileria parasites is an informative marker for species discrimination. Int J Parasitol 2000; 30: 1181-1185.

Chvostac M, Spitalska E, Vaclav R, Vaculova T, et al. Seasonal patterns in the prevalence and diversity of tick-borne Borrelia burgdorferi sensu lato, Anaplasma phagocytophilum and Rickettsia spp. in an urban temperate forest in South Western Slovakia. Int J Environ Res Public Health 2018; 15:994.

Dumitrache MO, Pastiu AI, Kalmar Z, Mircean V, et al. Northern white-breasted hedgehogs Erinaceus roumanicus as hosts for ticks infected with Borrelia burgdorferi sensu lato and Anaplasma phagocytophilum in Romania. Ticks Tick Borne Dis 2013; 4:214-217.

Duron O, Noel V, McCoy KD, Bonazzi M, et al. The recent evolution of a maternally-inherited endosymbiont of ticks led to the emergence of the $\mathrm{Q}$ fever pathogen, Coxiella burnetii. PLoS Pathog 2015a; 11:e1004892.

Duron O, Sidi-Boumedine K, Rousset E, Moutailler S, et al. The importance of ticks in $\mathrm{Q}$ fever transmission: what has (and has not) been demonstrated? Trends Parasitol 2015b; 31: 536-552.

Eldin C, Melenotte C, Mediannikov O, Ghigo E, et al. From Q fever to Coxiella burnetii infection: a paradigm change. Clin Microbiol Rev 2017; 30:115-190.

Fard SN, Khalili M. PCR-detection of Coxiella burnetii in ticks collected from sheep and goats in Southeast Iran. Iran J Arthropod Borne Dis 2011; 5:1-6.
Han DG, Ryu JH, Chae JB, Kim DW, et al. First report of Anaplasma phagocytophilum infection in Holstein cattle in the Republic of Korea. Acta Trop 2018; 183:110-113.

Han YJ, Park J, Lee YS, Chae JS, et al. Molecular identification of selected tick-borne pathogens in wild deer and raccoon dogs from the Republic of Korea. Vet Parasitol Reg Stud Reports 2017; 7:25-31.

Hilpertshauser H, Deplazes P, Schnyder M, Gern L, et al. Babesia spp. identified by PCR in ticks collected from domestic and wild ruminants in southern Switzerland. Appl Environ Microbiol 2006; 72:6503-6507.

Homer MJ, Aguilar-Delfin I, Telford SR, 3rd, Krause PJ, et al. Babesiosis. Clin Microbiol Rev 2000; 13:451-469.

Jaimes-Duenez J, Triana-Chavez O, Mejia-Jaramillo AM. Genetic, host and environmental factors associated with a high prevalence of Anaplasma marginale. Ticks Tick Borne Dis 2018; 9:1286-1295.

Kang JG, Ko S, Kim YJ, Yang HJ, et al. New genetic variants of Anaplasma phagocytophilum and Anaplasma bovis from Korean water deer (Hydropotes inermis argyropus). Vector Borne Zoonotic Dis 2011; 11:929-938.

Kim BJ, Oh DH, Chun SH, Lee SD. Distribution, density, and habitat use of the Korean water deer (Hydropotes inermis argyropus) in Korea. Landsc Ecol Eng 2011; 7:291-297.

Ko S, Kim SJ, Kang JG, Won S, et al. Molecular detection of Bartonella grahamii and B. schoenbuchensis-related species in Korean water deer (Hydropotes inermis argyropus). Vector Borne Zoonotic Dis 2013; 13:415-418.

Kumar S, Stecher G, Tamura K. MEGA7: molecular evolutionary genetics analysis version 7.0 for bigger datasets. Mol Biol Evol 2016; 33:1870-1874.

Lee M, Seo MG, Lee SH, Ouh IO, et al. Molecular detection and phylogenetic analysis of tick-borne pathogens in wild Korean water deer and farmed elk in Gyeongbuk and Gangwon Provinces of Korea. J Vet Med Sci 2018; 80:1473-1478.

Lee M, Yu D, Yoon J, Li Y, et al. Natural co-infection of Ehrlichia chaffeensis and Anaplasma bovis in a deer in South Korea. J Vet Med Sci 2009; 71:101-103.

Lempereur L, Wirtgen M, Nahayo A, Caron Y, et al. Wild cervids are host for tick vectors of Babesia species with zoonotic capability in Belgium. Vector Borne Zoonotic Dis 2012; 12:275-280.

Li H, Zheng YC, Ma L, Jia N, et al. Human infection with a novel tick-borne Anaplasma species in China: a surveillance study. Lancet Infect Dis 2015; 15:663-670.

Lu M, Tian JH, Yu B, Guo WP, et al. Extensive diversity of rickettsiales bacteria in ticks from Wuhan, China. Ticks Tick Borne Dis 2017; 8:574-580.

Majazki J, Wuppenhorst N, Hartelt K, Birtles R, et al. Anaplasma phagocytophilum strains from voles and shrews exhibit specific ankA gene sequences. BMC Vet Res 2013; 9:235.

Malandrin L, Jouglin M, Sun Y, Brisseau N, et al. Redescription of Babesia capreoli (Enigk and Friedhoff, 1962) from roe deer (Capreolus capreolus): isolation, cultivation, host specificity, molecular characterisation and differentiation from Babesia divergens. Int J Parasitol 2010; 40:277-284.

Massung RF, Levin ML, Munderloh UG, Silverman DJ, et al. Isolation and propagation of the Ap-Variant 1 strain of Anaplasma phagocytophilum in a tick cell line. J Clin Microbiol 2007; 45:2138-2143.

Norlander L. Q fever epidemiology and pathogenesis. Microbes Infect 2000; 2:417-424.

Parisi A, Fraccalvieri R, Cafiero M, Miccolupo A, et al. Diagnosis of Coxiella burnetii-related abortion in Italian domestic 
ruminants using single-tube nested PCR. Vet Microbiol 2006; 118:101-106.

Penzhorn BL. Babesiosis of wild carnivores and ungulates. Vet Parasitol 2006; 138:11-21.

Razanske I, Rosef O, Radzijevskaja J, Bratchikov M, et al. Prevalence and co-infection with tick-borne Anaplasma phagocytophilum and Babesia spp. in red deer (Cervus elaphus) and roe deer (Capreolus capreolus) in Southern Norway. Int J Parasitol Parasites Wildl 2019; 8:127-134.

Sato M, Nishizawa I, Fujihara M, Nishimura T, et al. Phylogenetic analysis of the $16 \mathrm{~S}$ rRNA gene of Anaplasma species detected from Japanese serows (Capricornis crispus). J Vet Med Sci 2009; 71:1677-1679.

Seo MG, Lee SH, VanBik D, Ouh IO, et al. Detection and genotyping of Coxiella burnetii and Coxiella-like bacteria in horses in South Korea. PLoS One 2016; 11:e0156710.

Seo MG, Ouh IO, Lee H, Geraldino PJL, et al. Differential identification of Anaplasma in cattle and potential of cattle to serve as reservoirs of Anaplasma capra, an emerging tickborne zoonotic pathogen. Vet Microbiol 2018; 226:15-22.

Seong G, Han YJ, Oh SS, Chae JS, et al. Detection of tick-borne pathogens in the Korean water deer (Hydropotes inermis argyropus) from Jeonbuk province, Korea. Korean J Parasitol 2015; 53:653-659.

Shin GW, Kim EJ, Lee HB, Cho HS. The prevalence of Coxiella burnetii infection in wild Korean water deer, Korea. J Vet Med Sci 2014; 76:1069-1071.

Sprong H, Tijsse-Klasen E, Langelaar M, De Bruin A, et al. Prevalence of Coxiella burnetii in ticks after a large outbreak of Q fever. Zoonoses Public Health 2012; 59:69-75.
Sun XF, Zhao L, Wen HL, Luo LM, et al. Anaplasma species in China. Lancet Infect Dis 2015; 15:1263-1264.

VanBik D, Lee SH, Seo MG, Jeon BR, et al. Borrelia species detected in ticks feeding on wild Korean water deer $(\mathrm{Hy}$ dropotes inermis) using molecular and genotypic analyses. J Med Entomol 2017; 54:1397-1402.

Yang J, Liu Z, Niu Q, Liu J, et al. A novel zoonotic Anaplasma species is prevalent in small ruminants: potential public health implications. Parasit Vectors 2017; 10:264.

Yang J, Tian Z, Liu Z, Niu Q, et al. Novel spotted fever group rickettsiae in Haemaphysalis qinghaiensis ticks from Gansu, Northwest China. Parasit Vectors 2016; 9:146.

Yin H, Liu Z, Guan G, Liu A, et al. Detection and differentiation of Theileria luwenshuni and T. uilenbergi infection in small ruminants by PCR. Transbound Emerg Dis 2008; 55: 233-237.

Zintl A, Mulcahy G, Skerrett HE, Taylor SM, et al. Babesia divergens, a bovine blood parasite of veterinary and zoonotic importance. Clin Microbiol Rev 2003; 16:622-636.

Address correspondence to: Kyoung-Seong Choi

Department of Animal Science and Biotechnology College of Ecology and Environmental Science Kyungpook National University Sangju 37224 Republic of Korea

E-mail: kschoi3@knu.ac.kr 